\title{
ASERFO, a concrete example of collaboration between industries and academia to develop students' skills in know-how, entrepreneurship and behavior
}

\section{Laurent Mazuray, Francois Balembois}

Laurent Mazuray, Francois Balembois, "ASERFO, a concrete example of collaboration between industries and academia to develop students' skills in know-how, entrepreneurship and behavior," Proc. SPIE 9946, Optics

Education and Outreach IV, 99460H (27 September 2016); doi:

$10.1117 / 12.2236156$

EDent: SPIE Optical Engineering + Applications, 2016, San Diego, California, United States 


\title{
ASERFO, a concrete example of collaboration between industries and academia to develop students' skills in know-how, entrepreneurship and behavior
}

\author{
Laurent Mazuray*a ${ }^{*}$, Francois Balembois**b \\ ${ }^{a}$ Former chairman of ASERFO - Invited teacher at Institut d'Optique Graduate School and \\ universities - Head of Satellites Programs' Procurement France, Airbus Defence \& Space; ' Dean of \\ studies, Institut d'Optique Graduate School, Orsay, France \\ *laurent.mazuray@airbus.com; phone+33-626271980 \\ **francois.balembois@institutoptique.fr
}

\begin{abstract}
Photonics is present into several industries. Further development implies efficient link from innovation to application. For that purpose, optics education at universities is key, not only to teach the fundamental physics, but for students to develop their know-how, entrepreneurship and behavior, because:

$\checkmark \quad$ Photonics is often part of systems, requesting the mastering of development tools and processes used by industries,

$\checkmark \quad$ Innovations require an entrepreneur spirit,

$\checkmark \quad$ Industries are organized per projects for optical developments in which optical specialists have to interact with other fields and people in a plateau.

This is why universities shall develop ecosystems where students, researchers, teachers and industries meet and foster the acquisition of these above three skills by the students.

ASERFO, French association of optics industries (Thales, Airbus, CEA, Essilor...), worked at promoting this ecosystem by funding, advising and supporting the training at the Institut d'Optique Graduate School (IOGS) as an industrial advisory committee.

It is proposed to present this approach and talk on concrete initiatives implemented by Institut d'Optique Graduate School with regard to these industrial skills.
\end{abstract}

Keywords: know-how, entrepreneurship, behavior, ecosystem, education, industry, engineer

\section{INTRODUCTION}

Photonics as light science and technologies has shown a dramatic increase over the past ten years. Many applications and uses have been revolutionized by photonics. Benefiting of low cost components developed in the last years, photonics is an incredible reservoir of innovations. Further development implies efficient link from innovation to application. For that purpose, optics education at universities or graduate schools is key in order to graduate engineers which will be capable to capture and use innovation. The problematic can be then expressed as follows:

$>$ What are the skills needed for this?

$>$ How can universities foster their acquisition by the students?

$>$ How universities which primary mission is to bring the academic knowledge can be efficient enablers of this?

These are questions Institut d'Optique Graduate School (IOGS) and ASERFO have tried to answer together through a set of initiatives. This paper first expresses the skills expected from the engineers and the best way for them to acquire it. Then we present ASERFO, French association of optics industries which worked at promoting an ecosystem at IOGS. 
Last we detail the concrete initiatives implemented in order to fit to objectives and expectations, and the results achieved which are very strong assets for the students graduated.

\section{A BRIEF OVERVIEW OF THE SKILLS EXPECTED FROM THE ENGINEERS}

\subsection{Engineers are the owners of an industrial process, product delivery oriented}

Dictionary states that "Engineers are persons who design and built things to solve specific problems and bring solutions". Engineers are so recognized as the owners of a specific industrial process allowing the design, production and delivery of concrete products [figure $1 \mathrm{left}$ ]. This industrial process is based on three pillars which are to be fulfilled for a successful product delivery: these are the On-Time, On-Cost and On-Quality delivery [figure 1 right].
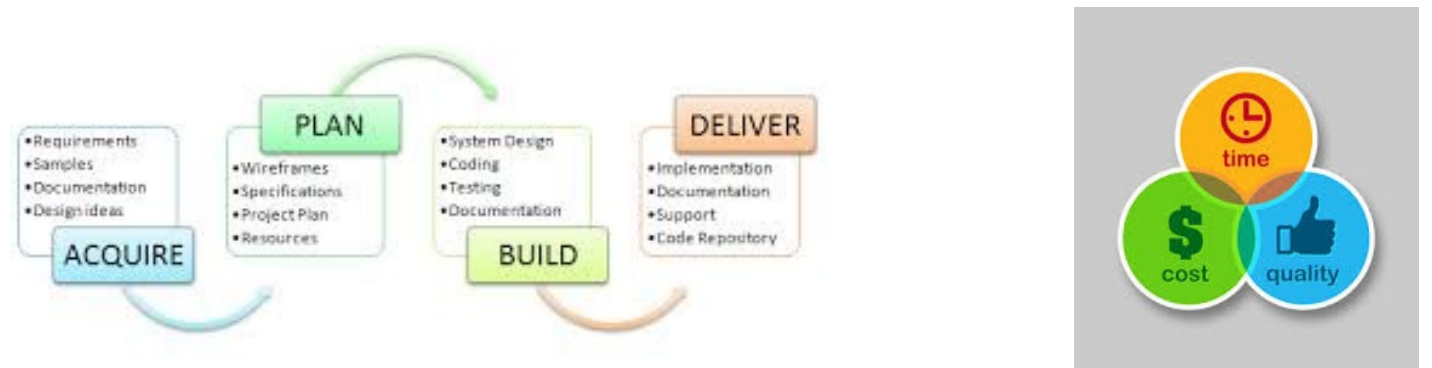

Figure 1: left: main steps of an industrial process which shall be owned by the engineers. Right: the 3 pillars of a successful product delivery.

This industrial engineering process, to be successfully mastered, implies students learn fundamental physics, obviously, but also develop their know-how, entrepreneurship and behavior, because:

$\checkmark \quad$ Photonics is often part of systems, requesting the mastering of development tools and processes used by industries,

$\checkmark \quad$ Innovations require an entrepreneur spirit,

$\checkmark \quad$ Industries are organized per projects for optical developments in which optical specialists have to interact with other fields and people in a plateau.

Lets' elaborate a bit what know-how, entrepreneurship and behavior means.

\subsection{Know-how, entrepreneurship and behavior: the three main skills to master the engineering process}

Know-how: the engineers shall be capable to start their work from a set of requirements coming from a customer not having a high technical background, as it is the case in B-to-C (Business to Customer). These requirements are sometimes not that consistent or clear. More, some requirements can be in contradiction. From this set, engineers shall draw the best design or more generally speaking the best technical solution in consideration of the schedule and cost imposed.

This implies a long flow of activities such as requirements analysis, clarifications, design trade-off, risk mitigation decisions, analyses, internal discussions, external discussions with customer or with suppliers, iterations, product policy reconciliation, reviews, tests, work, rework, recovery...to be put in a right order and a right way in order to, at the end, converge and succeed to produce and deliver the product in compliance to customer expectation.

The two examples of System Development Life Cycle [figure 2] illustrate this process: at each step, technical knowledge is present to serve the successful achievement of the step. Such achievement is the necessary condition to go to the next step up to a successful product delivery. Capability of the engineers to master and run this process is know-how.

It is always amazing to see in the courses students capable to execute with a high level of mastering complex calculations from a well given problematic expressed in a technical language, where they become very embarrassed when the same problematic is expressed in an end-to-end mission objective in a "customer" language, and lead to implement a system 
design process starting first with the need to translate the requirements into a technical language and flow-down them from system to equipment. This know-how is a major differentiator for the innovative industries.
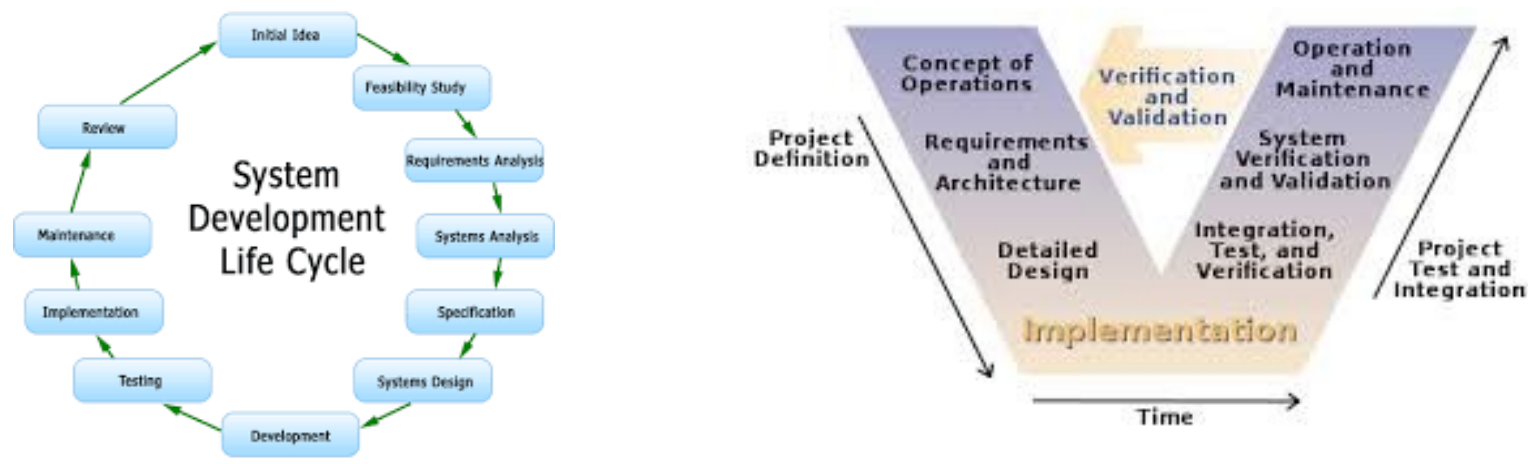

Figure 2: System development cycle (Round or V-shape) defining the process to run for a successful product development. Engineering is a process. Capability of the engineers to master and run this process is know-how.

The two other skills which are entrepreneurship and behavior can be categorized as soft skills in comparison to hard skill which is the set of all technical knowledge acquired by the students through the physic courses.

Entrepreneurship is a spirit allowing to capture, develop or use innovation [figure 3]: curiosity and willingness to innovate are obviously the trigger. But in a complex world where nothing is "pre-revealed" the entrepreneur shall start from a confused and huge set of various, unclear, partial and unstable information, from which he shall be capable to:

1. Identify opportunities,

2. Envision the possibilities,

3. Draw and implement a suitable action plan.

Such capability is neither obvious nor a common quality shared by all human being. But at the end this is a quality expected from innovative industries.
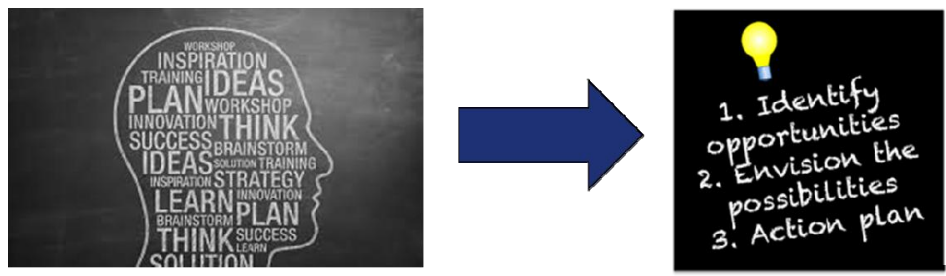

Figure 3: Illustration of the entrepreneurship spirit: this mindset is a quality expected from innovative industries

Behavior: photonic industry is mainly organized per projects in which optical specialists have to interact with other people from technical as well as from non-technical domains. How to create value from the accumulation of single competences and ideas? This is the famous $1+1=3$ contradicting the rules of mathematics we used to say to illustrate how people working as a team can be an extremely powerful way of generating ideas and solutions [figure 4]: like a football team, engineers shall be capable to act, interact and be engaged in a community, at the service of a common objective which is the product delivery.

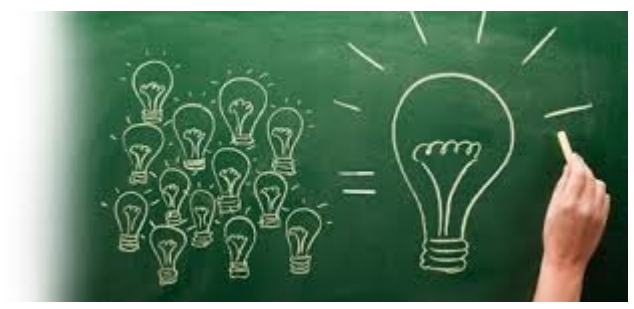

Figure 4: Illustration of the behavior: this mindset is a quality expected from the engineers. 


\subsection{A common language and metric is needed for industry to capture and use innovation}

Industry needs for growth engineers capable to capture innovation. Making innovation concrete requires the convergence of several actors from various horizons, which shall work together in a fully interleaved manner. Figure 5 illustrates this: academia and government labs are the first step for innovation with basic or applied research. Then they interact with entrepreneurs for technical development, later followed by prototypes and systems developments often taken over by larger companies. Engineers shall be capable to master these interactions. Students should so acquire this capability.

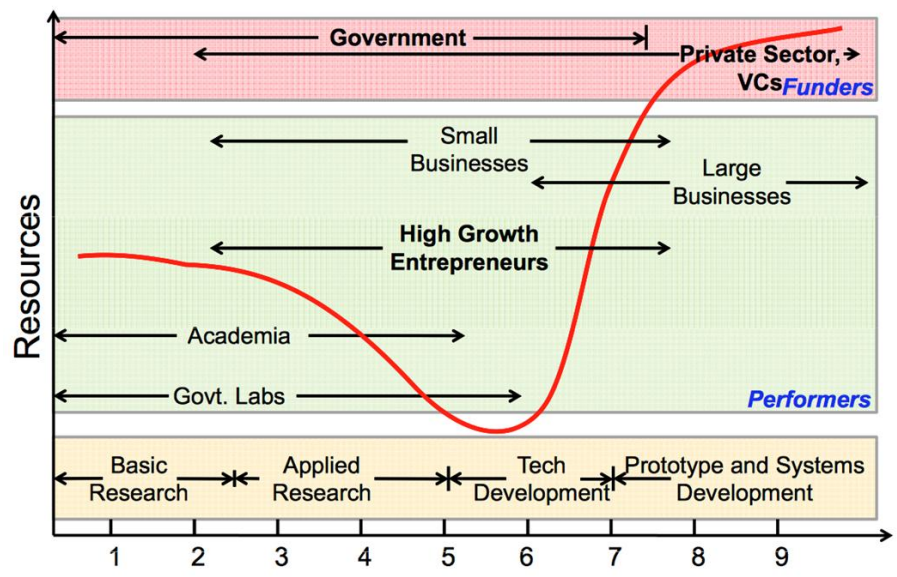

Figure 5: Illustration of the interactions between research and industry from an idea up to its use. Engineers shall be capable to master these interactions. Students should acquire this capability during their studies.

To interact implies to be capable to communicate and understand each other. A common language and metric appears so to be necessary in order to answer to the below questions:

$\checkmark$ How is this idea / research / techno mature for use in the optical system?

$\checkmark$ Is this choice of implementation the best for the system?

$\checkmark$ What activities are to be implemented for a robust and safe development?

$\checkmark$ What are the risks and how to mitigate them?

$\checkmark$ Which cost and schedule to foresee for the development?

Technology Readiness Levels (TRL) is a systematic metric/measurement system that supports assessment of the maturity of a particular technology and the consistent comparison of maturity between different types of technology. We will not develop this further as we already presented it in a former SPIE OSD conference. Lets' however remind the scale which should be a common language for whole community. Figure 6 is extracted from NASA standards.

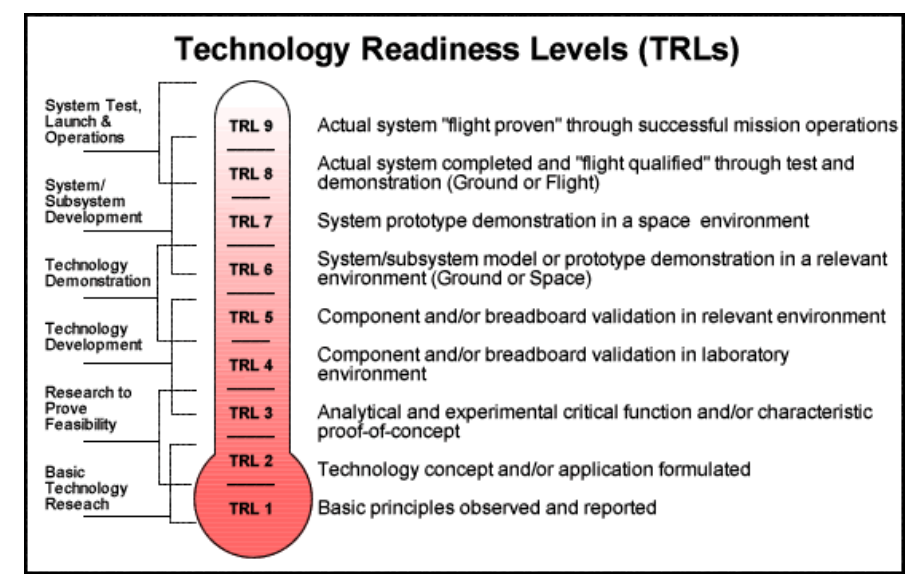

Figure 6: Technology Readiness Levels is a common language for mastering the capture and use of innovations. 
For successful implementation of innovation, it is essential to map the path from concept to product implementation. TRL is a key element in planning the path across Death Valley transition positioning funding lines correctly with targets and objectives for the next step [figure 7]:

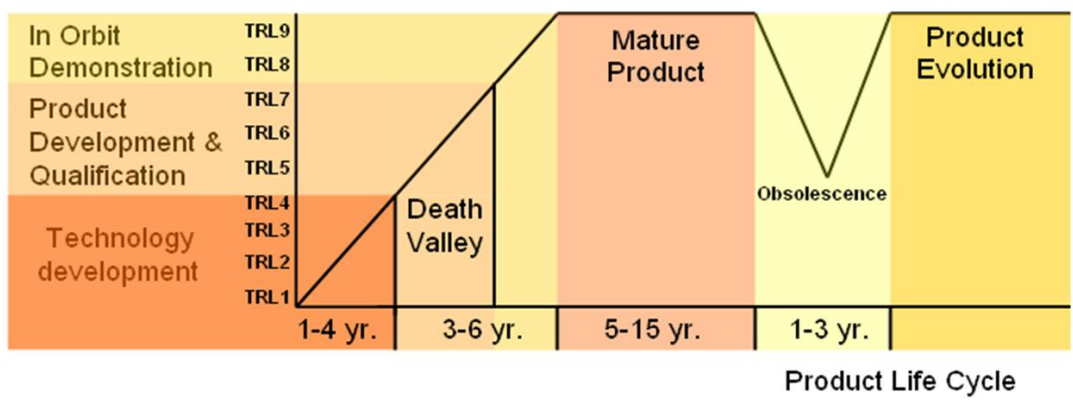

Figure 7: Example of TRL application: product Life cycle for a satellite using TRL scale as a metric.

As consequence of all what has been developed above, such interleaved and multi-actors collaboration needs an ecosystem where students, researchers, teachers and industries meet and foster the acquisition of these skills by the students [Figure 8].

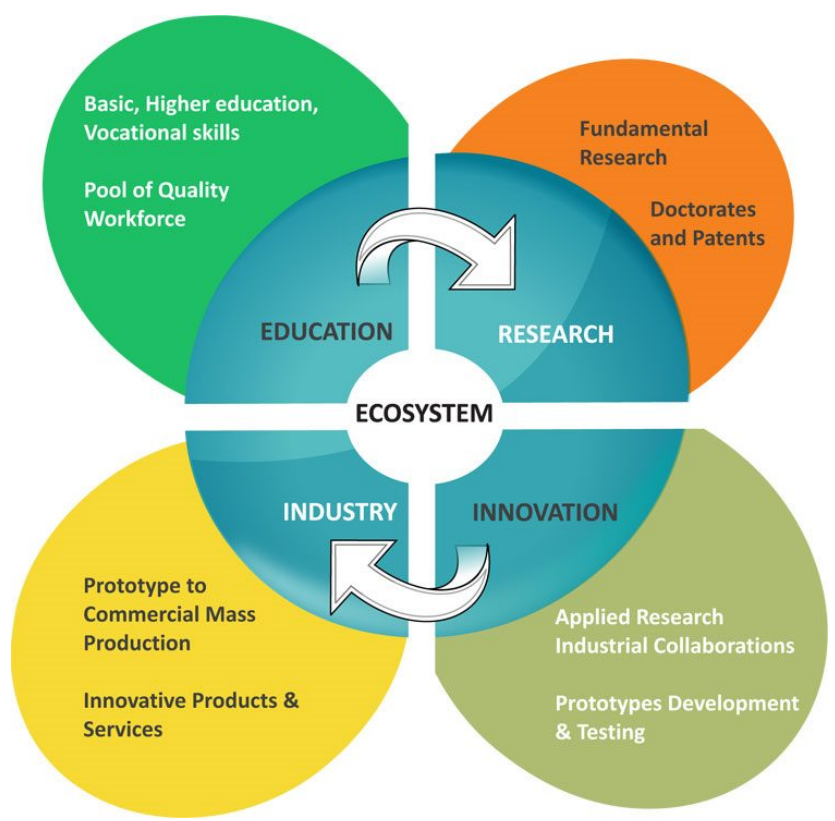

Figure 8: A visual description of the ecosystem to be developed for allowing students to master the engineering industrial process. ASERFO, French association of optics industries worked at promoting this ecosystem. 


\section{THE ECOSYSTEM FOSTERED BY ASERFO AND IMPLEMENTED BY IOGS}

\subsection{Presentation of ASERFO}

ASERFO, French association of optics industries (Thales, Airbus, CEA, Essilor...) [figure 9], worked at promoting an ecosystem where students, researchers, teachers and industries meet and foster the acquisition by the students of these skills described above, by funding, advising and supporting the training at the Institut d'Optique Graduate School, as an industrial advisory committee. Three main streams to be highlighted are:

$\checkmark$ Teaching portfolio review against industries' expectation,

$\checkmark$ Identification of new trainings oriented "projects' development",

$\checkmark$ Appointment of invited teachers from industries' pool of engineers.

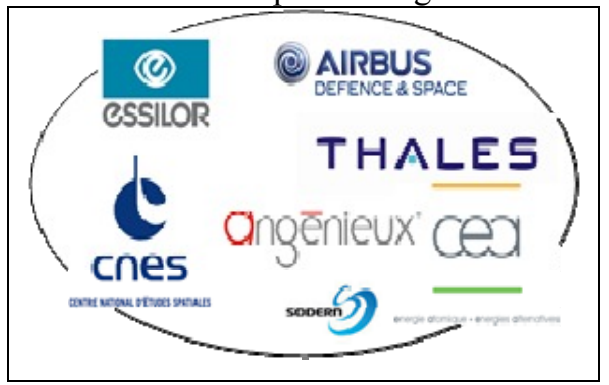

Figure 9: majors companies in the domain of the optical sensors were member of ASERFO... working as an industrial advisory committee toward Institut d'Optique Graduate School (IOGS)

Founded in 1917, Institut d'Optique Graduate School is a European leader for higher education in Photonics. As a French "Ecole d'ingénieur", IOGS has an intake of over 150 students per year. IOGS offers the broadest scope in the field of photonics and optical sciences and engineering in Europe. Its international reputation is built on: high quality academic and practical education, major scientific contributions of its research center and close ties with industry.

\subsection{Presentation of the four assets implemented by Institut d'Optique Graduate School (IOGS)}

\subsubsection{Asset 1: Industry tools, language and methods are teach through specific "project management" courses}

Let's illustrate briefly some tools and methods teach, always referring to the three pillars presented above which are the On-Time, On-Cost, and On Quality delivery [figure 10]:

$>$ V-shape development cycle

$>$ Specification flow-down and reconciliation

$>$ System design road-map

$>$ Activity logic and schedule optimization

$>$ Cost management and mastering

$>$ Risk management and mitigation

$>$ Schedule analysis and critical path optimization

$>$ Value Stream Mapping

$>$ Design-to-cost, Design-to-manufacture

$>$ KPIs...

Everybody can recognize there as being commonly and largely used by industry. Students must master these.
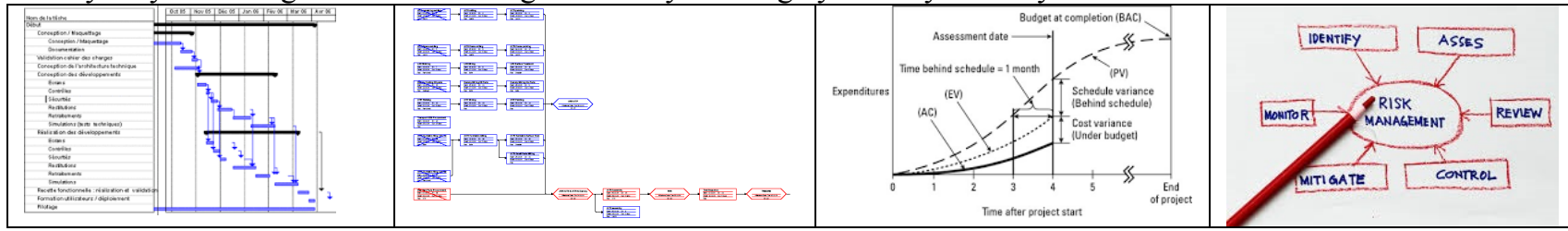

Figure 10: some illustration of commonly and largely tools used for On-Time, On-Cost, On-quality delivery 


\subsubsection{Asset 2: experimental resources, the way to develop practical skills in photonics}

Institut d'Optique Graduate School has placed strong emphasis on hands-on training, which is inseparable from top-level classroom training. Some clear features to illustrate this concretely:

$\checkmark$ Lab-work is a high portion of the time spent by the students: 100 to 200 hours per year,

$\checkmark$ Over 150 experiments are proposed to students,

$\checkmark$ Lab-work teaching involves 70 researchers, engineers, assistant professors and professors to guide the students 150 which is a huge ratio,

Experiments are maintained up-to-date to reflect the most recent advances in all areas of photonics.

Institut d'Optique Graduate School provides its students with opportunities to perform top-level labwork in quantum physics (source of entangled photons, saturated absorption), instrumental optics (adaptive optics, phase-shifting interferometer, etc.), lasers (holography, interferometry, optical parametric oscillators, etc. ) and optical telecommunications (erbium-doped fibre amplifiers, $10 \mathrm{~Gb} / \mathrm{s}$ digital transmission). Examples are given in the followings [figure 11]:

$>$ Laser: experiments on a vast number of laser types, from HeNe lasers, laser diodes, and diode-pumped solidstate lasers, to pulsed lasers, fiber lasers, and optical parametric oscillators.

$>$ Instrumental optics: from the simplest experiments in first year on optical instruments (microscopes, afocal lens, etc.) to the study of aberrations, wavefront analysis, photometry, the measurement of the modulation transfer functions in optical systems and adaptive optics.

$>$ Wave optics: experiments involving diffraction, spatial filtering, holography, and interferometers followed by more complex labwork on the interference of polarised light and ellipsometry. Properties of speckle, speckle interferometry, photorefractive crystals and real-time holography are also studied.

$>$ Fiber optics and optical communication: this heading encompasses experiments on fiber optic characterisation (dispersion measurement and optical time-domain reflectometry) as well as experiments involving fibers (fiber optic gyroscopes, laser and fiber amplifiers, fiber-optic communication, Raman scattering in a fiber).

$>$ Measurement systems: optical and electronic sensors. This heading encompasses experiments with a strong focus on electronics and signal processing. The workings of devices such as sensors, optical and infrared detectors, infrared cameras and laser rangefinders are discussed.

$>$ Quantum physics, atomic physics, nanophysics: experiments in saturated absorption and generating plasmons. Creation of a source of entangled photons (violation of Bell's theorem).
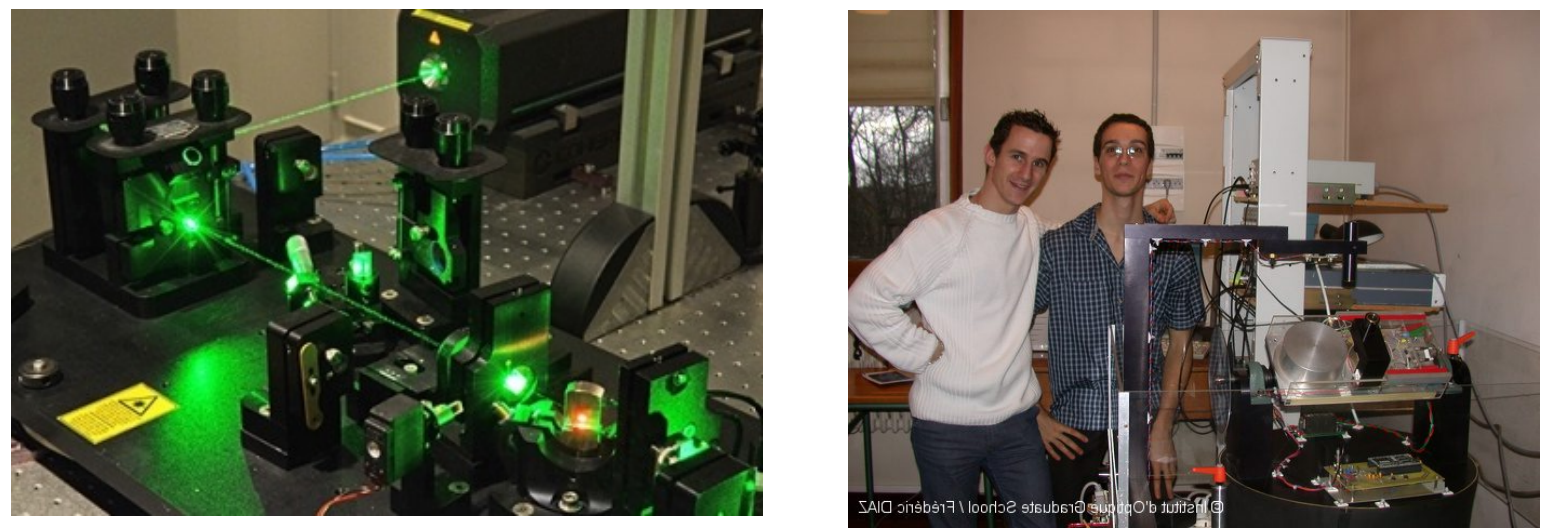

Figure 11: examples of experiments made at IOGS

ASERFO has played a key role in this topic, advising IOGS for the best choices of new technologies in photonics, and co-funding the lab-work facilities. 


\subsubsection{Asset 3: students' projects, a first real contact to industry}

Student at IOGS (first and second year of master degree) have to realize projects in close relation with the industry:

$\checkmark$ First action deals with understanding of the problematic,

$\checkmark$ Then working on specifications, the realization of the technical part is the main point of the project.

$\checkmark$ Last, the project ends with a presentation in front of teachers and engineers from the company involved in the project.

Projects can be related to many fields in photonics: head-up displays, spectral analysis of beauty creams, analysis of bidirectional reflectance distribution function for textiles, characterization of visual flux induced by street lamps, velocimetry by doppler effects using single frequency lasers...are some but not exhaustive concrete examples of achievements [figure 12].

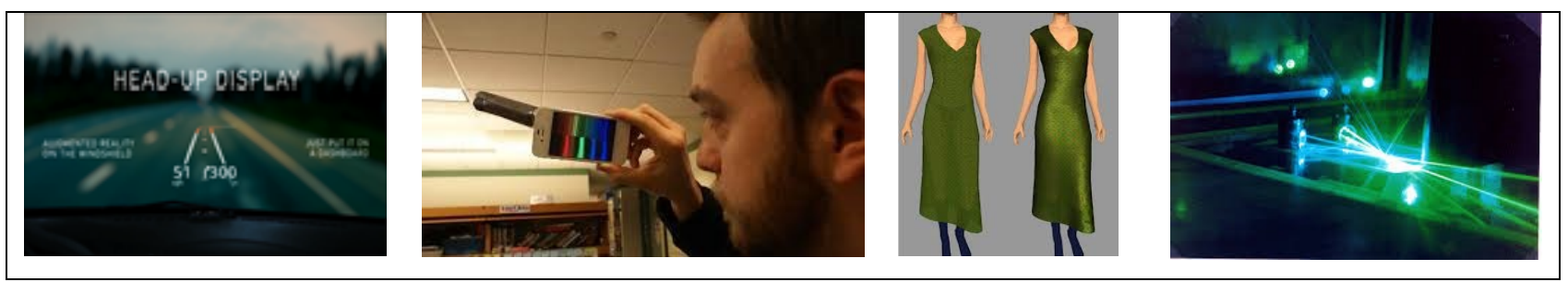

Figure 12: examples of projects made at IOGS (public illustrations)

A project is carried out by a group of students (2-4) with a supervisor of IOGS generally involved in the topics through his own topic of research. The time dedicated to the project represents 50 hours in master 1 and 100 hours in master 2.

\subsubsection{Asset 4: a full immersive entrepreneurial program and innovative ecosystem}

Last but not least, in 2006, IOGS has launched an entrepreneurship program over the three academic years of the curriculum. It corresponds to 550 hours, $30 \%$ of the total hours for graduation. 80 to 100 students join this program every year.

The goal is to stimulate entrepreneurial and innovation spirit, develop technology entrepreneurship and launch new high tech. ventures with students.

The program is organized in three steps:

$\checkmark$ Students are invited to work on their own ideas of start up in first year. The goal of the first part of the track is to approach customers and to sell ideas of products or services.

$\checkmark \quad$ In the beginning of the second year (September to December), students are immerged in specific fields of industry: for example, the smart city, the robot, airports...and are invited to find the problematics and ideas they have then to test with potential users and customers in order to adapt their offer in a multi-iterative process. This part of the program is built with industrials eager to interact with smart students to develop open innovation.

$\checkmark$ Starting from January of the second year to the end of the third year, students work on startup projects showing high potential value. The projects are collected from laboratories and companies by the staff of IOGS. All have a connection with photonics. Students, researchers and/or industrials work then together to develop the product, testing the market and realizing prototypes.

Several concrete results have been achieved through this program, far beyond the initial objective:

$>$ Over 100 projects have been investigated in ten years on the most innovative fields of photonics : urban lighting with LED, wind measurements by Lidars, 3D medical endoscopy, low cost silicon layer for photovoltaïc 
industry, optical authentication for security applications, nano-machining with femtosecond lasers, optical wireless network (LIFI), thermal imaging for industry, LED lighting for industrial vision...

$>$ Students from this entrepreneurial program have received 71 awards, 18 being international [figure 13]:

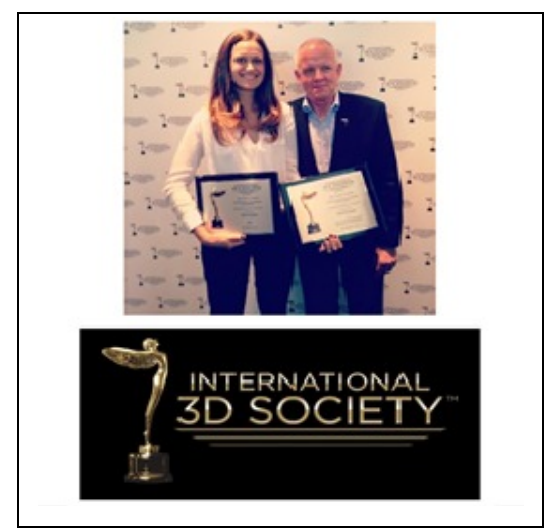

Figure 13: "3D technology Awards" Hollywood - September 2014 received for a project developed at IOGS in this entrepreneurial program

This program led to the creation of 15 startups founded by students or young graduates from the entrepreneurship program corresponding to 150 employees with a turnover of 7 million euros for FY 2015 [figure 14]:

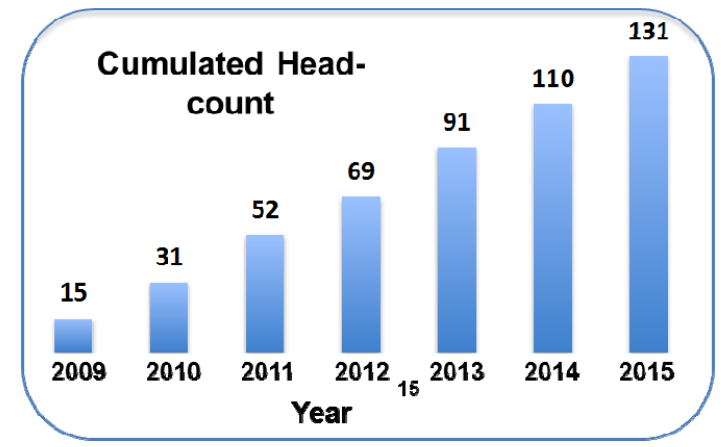

Figure 14: cumulated head-count from start-up created in the frame of this entrepreneurial program

The students having joined this program are more and more recognized by industry for their skills « ready for business ».

\subsection{Co-location is essential for developing a powerful ecosystem}

In the same building $(10,000 \mathrm{~m} 2)$, IOGS has gathered 30 starts up in photonics, funding structures, fablab and creative rooms, and teaching rooms able to welcome the 100 students of the entrepreneurship program [figure 15].

IOGS has an agreement with each company housed in the building: each of them agree to coach the students and advise them in key periods (test of prototypes, research of customers, research of funding...). For the projects, the help of companies acts as a real accelerator for the projects.

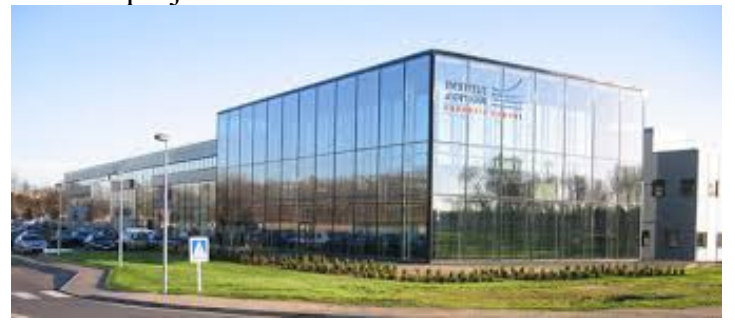

Figure 15: The IOGS main building where is implemented the ecosystem 


\subsection{This ecosystem also fosters the adaptation of the education with industry evolutions}

Engineering industrial processes are evolving fast: innovation lies now in design to manufacturing and design-to-cost drivers. This implies agile development instead of classical V-cycle approach, concurrent engineering and production approach [figure 16]. As example, the satellites' domain is currently leaving a revolution with several initiatives which OneWeb constellation in which Airbus Defence \& Space is highly involved, is an illustration: even if they have demonstrated their efficiency for launching high technology and reliable satellites, classical cycles are, for this type of application, too much time and cost consuming. Such new cycles or approaches are put in place leading today to a drastic cost and schedule reduction: "no one has ever built a satellite in one day...we will build several every day!" OneWeb said.
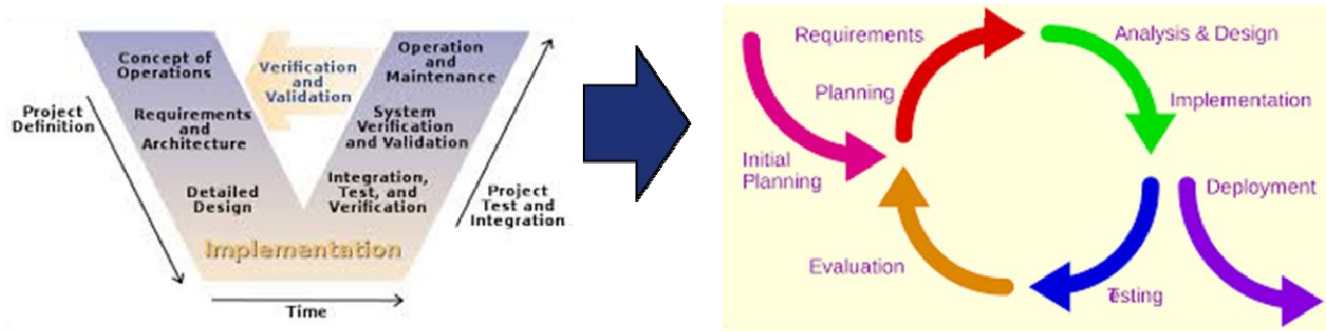

Figure 16: Illustration of the current evolution of the engineering processes

This proximity with industry allows the students to be trained on these up-to date processes.

\section{CONCLUSION}

The Institut d'Optique Graduate School (IOGS) has developed with the support of ASERFO as trigger and enabler an ecosystem in close relation with industry. ASERFO does not anymore exist as such in this "pull" mode: the proximity with industry and the associated state of mind is now spread over all courses.

Engineers graduated from IOGS are innovation champions: recent survey has shown that they patent four times more than the other engineers in France once having joined the industry.

They are also more eager to move at international: $25 \%$ graduated from the entrepreneurship program take their first job out of France, compared to $12 \%$ for the average in France.

The next step of development will be to welcome a highest ratio of international students excited by the industry proximity assets and to develop continuing international developments and partnership. 